\title{
URETEROCELE ASSOCIATED WITH A SINGLE COLLECTING SYSTEM OF THE INVOLVED KIDNEY
}

\author{
WOUTER F. J. FEITZ, M.D. \\ MICHAEL L. RITCHEY, M.D. \\ DAVID A. BLOOM, M.D.
}

From the Departments of Urology, Radboud University Hospital, Nijmegen,

The Netherlands, and University of Michigan Hospitals, Ann Arbor, Michigan

\begin{abstract}
Objective. This is a study concerning ureteroceles associated with a single collecting system of the involved kidney.

Methods. Over an eight-year period 9 children ( 5 boys, 4 girls) had a ureterocele subtending a single collecting system, whereas 63 children had duplex ureteroceles. Malformations of other organ systems were present in only 1 patient.

Results. Three patients have undergone surgical interventions: a trarisureteral incision of bilateral obstructive ureteroceles in 1 and nephroureterectomy in 2 . In 4 cases cystic/dysplastic kidneys involuted and were reabsorbed with collapse of the ureterocclcs. The last 2 patients have received antibiotic treatment for single episodes of a urinary tract infection.

Conclusions. Earlier reports of a high incidence of concomitant anomalies and male predominance in patients with single-system ectopic ureteroceles could not be verified by our experience. Our current policy for a patient is careful evaluation, individualized therapy, and long-term surveillance.
\end{abstract}

Congenital obstructive uropathy is currently usually diagnosed early in life by prenatal ultrasound. Hydronephrosis is the end result of obstruction at any level of the urinary tract. Prenatal diagnosis is providing the opportunity for longterm surveillance of many obstructive lesions that may lead to elucidation of their natural history. ${ }^{1}$ Ureteroceles are the third most common cause of prenatal hydronephrosis and usually obstruct the upper pole ureter in a duplex renal unit. ${ }^{2}$ Singlesystem ectopic ureteroceles are less common but are a distinct entity, with a reported male predominance and commonly associated with cardiac anomalies. ${ }^{3}$ We hereby report a review of our experience with single-system ureteroceles.

\section{MATERIAL AND METHODS}

Seventy-two patients with ureteroceles were evaluated by the pediatric urology service of the University of Michigan in the last eight years. Nine patients ( 5 boys, 4 girls) had a single collecting

Submitted: September 16, 1993, accepted (with revisions): December $15,199.3$ system of the involved kidney. The right kidney was involved in 3 , the left in 4 , and the single-system ureterocele was bilateral in 2 patients. Diagnostic evaluation included sonography, voiding cystourethrogram, intravenous urography, diuretic renogram, and, in some cases, cystourethroscopy. The diagnosis of congenital obstructive uropathy was made by prenatal ultrasound in 3 patients. Postnatal evaluation proved that the ureterocele obstructed a single collecting system of the kidney. In 3 additional patients the diagnosis was made before their first birthday. The other patients presented and were diagnosed at the age of seven, eleven, and sixteen years (Table I).

\section{RESULTS}

Four children never had symptoms related to their ureteroceles. These were the 3 diagnosed before birth and the newborn evaluated for esophageal atresia and tracheoesophageal fistula. The 5 others presented with urinary tract infection (2), pyelonephritis (1), sepsis (1), back pain, and hematuria (1). Concomitant urologic problems in 4 patients consisted of undescended testis 
TABLE I. Clinical findings

\begin{tabular}{|c|c|c|c|c|}
\hline Patient & $\begin{array}{c}\text { Age at } \\
\text { Diagnosis }\end{array}$ & Kidney Image & Therapy & $\begin{array}{l}\text { Findings on } \\
\text { Follow-Up (yr) }\end{array}$ \\
\hline 1 & Prenatal & Hydronephrosis & Nephrectomy & No urologic problems (2) \\
\hline 2 & Prenatal & Multicystic & Observation & Reabsorbed (2.5) \\
\hline 3 & Prenatal & Hydronephrosis & Observation & Reabsorbed (2.4) \\
\hline 4 & Day 3 & Multicystic & Observation & Reabsorbed (2.1) \\
\hline$b$ & 2.5 months & Dysplastic & Observation & Reabsorbed (1) \\
\hline 6 & 6 months & Hydronephrosis & Antibiotics & No urologic problems (1.6) \\
\hline 7 & 7 years & Dysplastic & Nephrectomy & Chronic renal failure (9) \\
\hline 8 & 11 years & $\begin{array}{c}\text { Bilateral hydro- } \\
\text { nephrosis }\end{array}$ & $\begin{array}{c}\text { Transurethral } \\
\text { ureterocele } \\
\text { incision }\end{array}$ & . \\
\hline 9 & 16 years & Normal & Antibiotics & No urologic problems (1) \\
\hline
\end{tabular}

(1), contralateral vesicoureteral reflux (3), and contralateral ureteropelvic junction obstruction for which a pyeloplasty was performed. This child also had a neurogenic bladder and eventually experienced chronic renal failure. In 6 patients and six renal units the kidney was nonfunctional (by renal nuclear scan). Involution of the nonfunctional kidneys occurred in 4 patients who experienced spontaneous collapse of the ureteroceles. These kidneys appeared as multicystic/dysplastic kidneys by ultrasound. An exact differentiation between an orthotopic or ectopic localization of the ureter orifice could not be made since a cystourethroscopy was only performed in the patient who underwent transureteral incision of bilateral obstructive ureteroceles and in the patient with small orthotopic ureteroceles diagnosed after a pyelonephritis at the age of sixteen years. In 2 patients a nephroureterectomy was performed because of a nonfunctioning kidney. Two patients have not required operative intervention. They have stable renal function although each has been treated for an episode of urinary tract infection and pyelonephritis (Table I).

\section{COMMENT}

The prenatal diagnosis of hydronephrosis has become commonplace due to the widespread use of prenatal ultrasonography. This knowledge is not always an advantage for parents, since it provokes concerns that cannot and need not be addressed until after birth. Furthermore, the natural history and course of hydronephrosis in many instances are not known. ${ }^{4}$ Early ultrasound diagnosis and treatment, however, have decreased the population of infants and children with severe infections from occult obstructive uropathy. ${ }^{5}$ A report by Johnson and Perlmutter ${ }^{3}$ suggested that patients with a single-system ectopic ureterocele have a male predominance and a strong risk of additional congenital anomalies. A report by Sen and Ahmed ${ }^{6}$ suggested an equal sex distribution, but they made no distinction between ectopic or intravesical orifices.

It is difficult to draw conclusions from our small group of patients. For example, we found no clear sex predominance or increased incidence of malformation of other organ systems. Our patient management is currently dictated by the functional status of the kidney. Nonfunctioning dysplastic renal units often involute and can be reabsorbed completely without requiring operative intervention. ${ }^{7}$ This might be one of the reasons for apparent renal agenesis that can be detected sonographically. Also, the bladder can be evaluated for the presence of a ureterocele in such a situation. Cases diagnosed prenatally with stable renal function can also be followed conservatively. Two of our patients, incidentally discovered to have ureteroceles, have maintained stable renal function with over one year of follow-up. Many diagnostic and treatment programs are currently employed in different centers, but large groups of patients with long-term analysis are needed before final conclusions can be made. $^{8-10}$

\section{CONCLUSION}

In our patients with a ureterocele associated with a single collecting system of the involved kidney, we found no clear sex predominance or increased incidence of malformation of other organ systems. Currently, our patient management is dictated by the functional status of the kidney and our policy for a patient is careful evaluation, individualized therapy, and long-term surveillance.

\footnotetext{
Wouter F. J. Feitz, M.D. Department of Urology University Hospital Nijmegen P.O. Box 9101 6500 HB Nijmegen, The Netherlands
} 
ACKNOWLEDGMLNT. This study was supported by The Netherlands Kidney Foundation C91.1166 and the Dutch Urological Research Foundation.

\section{REFERENCES}

1. Colodny AH: Fetal diagnosis and therapy: legal, ethical, religious, moral issues. Dial Pediatr Urol 9: 1-2, 1986.

2. Bloom DA, and Belman AB: Ectopic ureter and ureterocele, in Retik $A B$, and Cukier J (Eds): Pediatric Urology, Baltimore, Williams \& Wilkins, 1987, vol 14, pp 166-183.

3. Johnson DK, and Perlmutter AD: Single system ectopic ureteroceles with anomalies of the heart, testis and vas deferens. J Urol 123: 81--83, 1980 .

4. Koff SA, and Cambell K: Nonoperative management of unilateral neonatal hydronephrosis. J Urol 148: 525-531, 1992

5. Gross RE, and Clatworthy HW Jr: Ureterocele in in- fancy and childhood. Pediatrics 5: 68-77, 1950

6. Sen S, and Ahmed 5: 5ingle system ureteroceles in childhood. Aust NZ J Surg 58: 903-907, 1988.

7. Blaine CE, Ritchey ML, DiPietro MA. Sumida R. and Bloom DA: Single system ectopic ureters and ureteroceles associated with dysplastic kidney. Pediatr Radiol 22: 217-220. 1992

8. Argueso LR, Ritchey ML, Boyle ET Jr, Milliner DS, Bergstralh EJ, and Kramer SA: Prognosis of children with solitary kidney after unilateral nephrectomy. J Urol 148: $747-751,1992$

9. Maizels M, Reisman ME, Flom LS, Nelson J, Fernbach $S$, Firlit CF, and Conway JJ: Grading nephroureteral dilatation detected in the first year of life: correlation with obstruction. J Urol 148: 609-614, 1992.

10. Mor Y, Ramon J, Raviv G, Jonas P, and Goldwasser B: A 20 year experience with treatment of ectopic ureteroceles. J Urol 147: 1592-1594, 1992. 